\section{Epidural sufentanil does not attenuate the central haemodynamic effects of Caesarean section performed under epidural anaesthesia}

Edward T. Crosby MD FRCPC, Gregory L. Bryson MD, Robert D. Elliott MD FRCPC, C. Gverzdys MD FRCPC.
The effect of sufentanil $30 \mu \mathrm{g}$ added to the epidural local anaesthetic solutions used for anaesthesia during elective Caesarean section on central haemodynamic variables was studied. Haemodynamic measurements made by thoracic electrical bioimpedance (TEB) monitoring were compared in 21 healthy parturients undergoing Caesarean section under epidural anaesthesia with and without the addition of epidural sufentanil. The patients were randomized to control (Group C) and study (Group S) groups. Following iv prehydration, an epidural catheter was placed at the $L_{2-3}$ or $L_{3-4}$ interspace. After a negative test dose, in a double-blinded protocol, patients in Group $S$ received sufentanil $30 \mu \mathrm{g}(0.6 \mathrm{ml})$ in $4.4 \mathrm{ml}$ lidocaine carbonate $2 \%$ with $5 \mu \mathrm{g} \cdot \mathrm{ml}^{-1}$ epinephrine and those in Group C received $5 \mathrm{ml}$ lidocaine carbonate $2 \%$ with epinephrine. Lidocaine carbonate $2 \%$ with $5 \mu \mathrm{g} \cdot \mathrm{ml}^{-1}$ epinephrine was then titrated to establish an anaesthetic level of $T_{4}$. Haemodynamic variables (heart rate, mean arterial blood pressure, cardiac index, ejection fraction and end-diastolic index) were measured non-invasively, continuously throughout the perioperative period. There were no differences noted in haemodynamic measurements between the groups at any time perioperatively. However, differences occurred within the groups when compared with baseline values.

\section{Key words}

ANAESTHESIA: obstetric;

ANAESTHETIC TECHNIQUES: epidural.

From the Department of Anaesthesia, University of Ottawa, Ottawa General Hospital, 501 Smyth Road, Ottawa, Ontario, K1H 8L6.

Presented in part at the Canadian Anaesthetists Society

Annual Meeting, June 1992, Toronto, Canada.

Address correspondence to: Dr. Edward T. Crosby,

Department of Anaesthesia, Ottawa General Hospital,

501 Smyth Road, Ottawa, Ontario, K1H 8L6.

Accepted for publication 25th November, 1993.
Heart rate was increased in both groups intraoperatively. Cardiac index was increased throughout the intraoperative period in Group $S$ but was less frequently elevated in Group C. Ejection fraction was increased throughout the perioperative period in Group $S$ but not in Group $C$. End-diastolic index increased following iv preloading in both groups and returned to baseline with induction of epidural block. Maternal haemodynamic measurements as assessed by TEB monitoring, during Caesarean section, were not altered by the addition of $30 \mu \mathrm{g}$ sufentanil to carbonated lidocaine for lumbar epidural anaesthesia.

Ce travail évalue les effets hémodynamiques produits par l'addition de sufentanil $30 \mu \mathrm{g}$ à une solution épidurale d'anesthésique local pendant la césarienne non urgente. Les mesures hémodynamiques effectuées par monitorage de la bioimpédance thoracique électrique (TEB) sont comparées chez 21 parturientes bien portantes soumises à une césarienne sous anesthésie épidurale avec ou sans ajout de sufentanil épidural. Les patientes sont assignées au hasard au groupe contrôle (groupe C) et au groupe d'étude (groupe S). Après hydratation $i v$, un cathéter épidural est introduit à l'espace $L_{2-3}$ ou $L_{3-4}$. Après une dose-test négative, les patientes du groupe $S$ reçoivent, à double insu, du sufentanil $30 \mu \mathrm{g}(0,6 \mathrm{ml})$ dans 4,4 $\mathrm{ml}$ de lidocaïne carbonatée $2 \%$ avec $5 \mu \mathrm{g} \cdot \mathrm{ml}^{-1}$ d'épinéphrine; celles du groupe C reçoivent $5 \mathrm{ml}$ de lidocaïne carbonatée $2 \%$ avec $5 \mu \mathrm{g} \cdot \mathrm{ml}^{-1}$ d'épinéphrine. Par la suite, suffisamment de lidocaïne carbonatée $2 \%$ avec $5 \mu \mathrm{g} \cdot \mathrm{ml}^{-1}$ d'épinéphrine est ajoutée pour obtenir un niveau à $T_{4}$. Les variables hémodynamiques (fréquence cardiaque, tension artérielle moyenne, index cardiaque, fraction d'éjection et index télédiastolique) sont mesurées par méthode non effractive continuelle pendant la période périopératoire. On ne note en aucun moment de différences significatives entre les groupes. Cependant, on trouve des différences à l'intérieur des groupes lorsqu'on les compare aux valeurs initiales. La fréquence cardiaque peropératoire augmente dans les deux groupes. Lïndex cardiaque peropératoire 
augmente souvent dans le groupe $S$ et moins fréquemment dans le groupe $C$. La fraction d'éjection periopératoire augmente dans le groupe $S$ mais non dans le groupe $C$. Lindex télédiastolique augmente après la précharge intraveineuse et revient à sa valeur initiale après l'épidurale. Pendant la césarienne, l'hémodynamique maternelle, telle que mesurée par $T E B$, n'est pas modifiée par l'ajout de $30 \mu \mathrm{g}$ de sufentanil à la lidocaïne carbonatée administrée pour l'anesthésie épidurale lombaire.

Clinically important changes in maternal haemodynamic measurements occur during pregnancy and these alterations are most pronounced during labour and delivery, including delivery by Caesarean section. 1,2 Maternal haemodynamic changes have been evaluated by both invasive and noninvasive techniques but the number of investigations has been limited by the lack of availability, until recently, of accurate, noninvasive techniques for assessing central haemodynamic activity. Impedance cardiography (thoracic electrical bioimpedance (TEB) cardiography) is a noninvasive technique capable of assessing central haemodynamics that has been shown to correlate well with invasive techniques in both pregnant and nonpregnant subjects. 3,4

Visceral pain referred to the chest occurs in some patients during Caesarean section performed under major regional anaesthesia and may be associated with nausea and vomiting. Exteriorization of the uterus appears to be a common inciting event and it is felt that peritoneal traction is responsible for the chest pain and nausea. The addition of fentanyl to the local anaesthetic solution used for the establishment of epidural blockade improves intraoperative analgesia, decreasing the incidence of visceral pain, nausea and vomiting. ${ }^{5-7}$ It is assumed with this improved intraoperative analgesia, that attenuation of the central haemodynamic changes that occur during operative delivery take place. However, there have been no studies to compare indices of cardiac performance in parturients undergoing Caesarean section under epidural anaesthesia with and without epidural opioids. In this randomized, double-blinded study, maternal haemodynamics measured by impedance cardiography were compared in women undergoing elective Caesarean section under lumbar epidural anaesthesia with and without the addition of epidural sufentanil. It was our hypothesis that the addition of sufentanil to the epidural local anaesthetic agent would result in attenuation of the central haemodynamic changes that occur during Caesarean section.

\section{Methods}

A prospective, randomized, double-blind protocol was approved by the hospital ethics committee. Healthy parturients, ASA Class I or II, between 38 and 42 wk ges- tation, undergoing elective Caesarean section under epidural anaesthesia, were eligible for the study. After written informed consent was obtained, patients were randomized, using a computer-generated table of random numbers, into study and control groups of 12 subjects each. Exclusion criteria included: lack of informed consent; contraindications to epidural anaesthesia; patients in active labour; pregnancies complicated by severe maternal medical conditions; and pregnancies complicated by hypertensive disorders (pregnancy-associated or chronic hypertension).

Patients were fasted overnight preoperatively and received $30 \mathrm{ml} 0.1 \mathrm{M}$ sodium citrate po on call to the operating room. A 16 ga $i v$ catheter was inserted into a forearm vein and a bolus of $20 \mathrm{ml} \cdot \mathrm{kg}^{-1}$ lactated Ringer's solution was administered before placement of the epidural catheter. An epidural catheter was placed at the $\mathrm{L}_{3-4}$ or $\mathrm{L}_{2-3}$ interspace using a 16 ga Tuohy needle. A test dose of $3 \mathrm{ml}$ lidocaine $1.5 \%$ with $5 \mu \mathrm{g} \cdot \mathrm{ml}^{-1}$ epinephrine was injected through the epidural catheter to verify appropriate placement of the catheter. Following the test dose, the patient received, in a double-blind protocol, either sufentanil $30 \mu \mathrm{g}(0.6 \mathrm{ml})$ in $4.4 \mathrm{ml}$ lidocaine carbonate $2 \%$ with epinephrine $5 \mu \mathrm{g} \cdot \mathrm{ml}^{-1}$ solution (total volume of $5 \mathrm{ml}$ ) (Group S), or $5 \mathrm{ml}$ lidocaine carbonate $2 \%$ with $5 \mu \mathrm{g} \cdot \mathrm{ml}^{-1}$ epinephrine (Group C). Increments of lidocaine carbonate $2 \%$ with epinephrine were then administered into the epidural space in 3-5 ml aliquots over ten minutes. The sensory level was approximated by lack of cold perception with an alcohol swab and the anaesthetic was titrated to achieve a sensory level between the fourth and sixth thoracic dermatomes. Surgery then commenced. Patients complaining of pain intraoperatively were asked to describe the pain and rate it on a ten-point visual analogue scale (VAS). These patients were treated with increments of sufentanil $i v, 10 \mu \mathrm{g}$, titrated, to effect. The occurrence of pain and the requirement for intraoperative $i v$ sufentanil supplementation were recorded as well as the nature and intensity of pain experienced. The occurrence of nausea and/or vomiting was also recorded, in addition to the time in the operation that the symptom occurred. Nausea was treated with droperidol $i v$ in increments of $0.5 \mathrm{mg}$. Following delivery of the placenta, an infusion of lactated Ringer's solution with oxytocin in a concentration of $20 \mathrm{IU} \cdot \mathrm{L}^{-1}$ at a rate of $125 \mathrm{ml} \cdot \mathrm{hr}^{-1}$ was started. Intraoperative hypotension, defined as a systolic blood pressure $<100 \mathrm{mmHg}$ or a decrease of greater than $20 \%$ from control, was treated with ephedrine $\dot{\omega}$ in $5 \mathrm{mg}$ increments.

Patients were monitored with a 3-lead ECG monitor, a pulse oximeter, and an automated, non-invasive blood pressure cuff set at three-minute intervals. Haemodynamic measurements (cardiac index, ejection fraction, and 
TABLE I Maternal demographics

\begin{tabular}{|c|c|c|}
\hline Character & $\begin{array}{l}\text { Group } S \\
\text { (Mean } \pm S D)\end{array}$ & Group C \\
\hline$n$ & 11 & 10 \\
\hline Age (yr) & $31 \pm 4.9$ & $30.9 \pm 5.3$ \\
\hline Height (cm) & $165.4 \pm 8.1$ & $162.2 \pm 5.4$ \\
\hline Weight (kg) & $76 \pm 13$ & $78 \pm 9.7$ \\
\hline ASA Class & ASA $1=11$ & ASA $I=9$, ASA II $=1$ \\
\hline $\begin{array}{l}\text { Number of thoracic } \\
\text { dermatomes blocked }\end{array}$ & $6.5 \pm 1.2$ & $6.4 \pm 1.1$ \\
\hline $\begin{array}{l}\text { Volume of lidocaine } \\
\text { administered }(\mathrm{ml})\end{array}$ & $20.3 \pm 3.8$ & $21.6 \pm 3.7$ \\
\hline
\end{tabular}

end-diastolic index) were determined continuously with a Bomed non-invasive cardiac monitor (Bomed model NCCOM3, Bomed Medical Manufacturing Ltd., Irvine, Calif, USA, 92718) and recorded at the following times: before insertion of the epidural catheter with the patient in the wedged supine position (Base); three minutes after insertion of the epidural catheter with the patient in the wedged supine position (Epi); after administration of the epidural test dose (Test); after establishment of the epidural block to the $T_{4}-T_{6}$ level (Blk); at the time of skin incision (Skin); at the time of cord clamping (Cord); five minutes after uterine exteriorization (UtOt); after uterine replacement (Utln); and following skin closure (Clse).

Haemodynamic measurements from the study and control groups were compared using ANOVA for repeated measures. Measurements made within the groups across time were compared using Tukey's HSD and the Newman-Keuls tests for multiple comparisons. The incidence of pain, nausea and vomiting was compared in the two groups using the Fisher's Exact Test. A $P$-value $<0.05$ was considered significant.

\section{Results}

Following written informed consent, 24 patients were randomized into the study. The data from three patients were removed from analysis because of incomplete data due to technical failure wherein there was difficulty in consistently obtaining haemodynamic data from the TEB computer (one patient) or an incomplete register of the haemodynamic data was made (two patients), leaving 11 patients in Group $S$ and ten in Group $C$. There was no difference in the demographic data between the two groups (Table I). Intraoperative pain occurred in one patient in each group and nausea and vomiting related to visceral stimulus occurred in two patients in Group C and one patient in Group S (Table II). Two patients in each group received ephedrine $10 \mathrm{mg}$ for hypotension, one in each group before delivery and one in each group after delivery. There were no differences noted in hae-
TABLE II Maternal symptoms

\begin{tabular}{|c|c|c|c|}
\hline Group patient $_{1}$ & Symptom & Event & Treatment \\
\hline$C_{10}$ & Nausea & $\begin{array}{l}\text { Uterine } \\
\text { exterionization } \\
\text { and closure }\end{array}$ & Droperidol $0.5 \mathrm{mg}$ \\
\hline \multirow[t]{2}{*}{$\mathrm{C}_{20}$} & Nausea & $\begin{array}{l}\text { Uterine } \\
\text { exteriorization }\end{array}$ & Droperidol $0.5 \mathrm{mg}$ \\
\hline & Pain & & \\
\hline $\mathrm{S}_{7}$ & Pain & $\begin{array}{l}\text { Uterine } \\
\text { exteriorization }\end{array}$ & Sufentanil $10 \mu \mathrm{g}$ \\
\hline $\mathrm{S}_{9}$ & $\begin{array}{l}\text { Nausea, } \\
\text { vomiting }\end{array}$ & Peritoneal closure & Droperidol $0.5 \mathrm{mg}$ \\
\hline
\end{tabular}

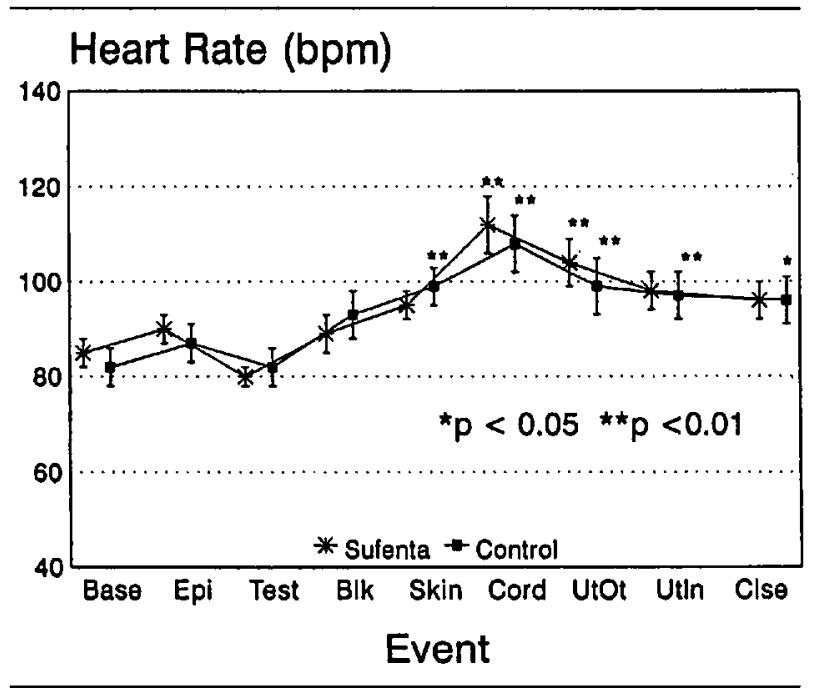

FIGURE 1 Maternal heart rate. The asterisks denote perioperative events at which the maternal heart rate was significantly different from the baseline values established in each group.

modynamic measurements between the groups at any time during the perioperative period. However, differences $(P<0.05)$ occurred within both Group $\mathrm{C}$ and $\mathrm{S}$ over time, when compared with baseline values. Maternal heart rate increased in Group C at the time of skin incision, cord clamping, uterine exteriorization and replacement and skin closure (Figure 1). In Group S, differences in heart rate occurred only at the time of skin incision and uterine exteriorization. Mean arterial pressure was less than baseline values only in Group $\mathrm{S}$ at the time of uterine replacement and skin closure (Figure 2). Cardiac index was increased in Group $S$ at the time of cord clamping, uterine removal and replacement and closure and was increased in Group $\mathrm{C}$ at skin incision and cord clamping (Figure 3). Ejection fraction was consistently increased in Group S from the time that the block had developed until the end of the surgery but was not changed in Group C (Figure 4). Finally, end diastolic index was increased in Group $S$ at the time of the epi- 


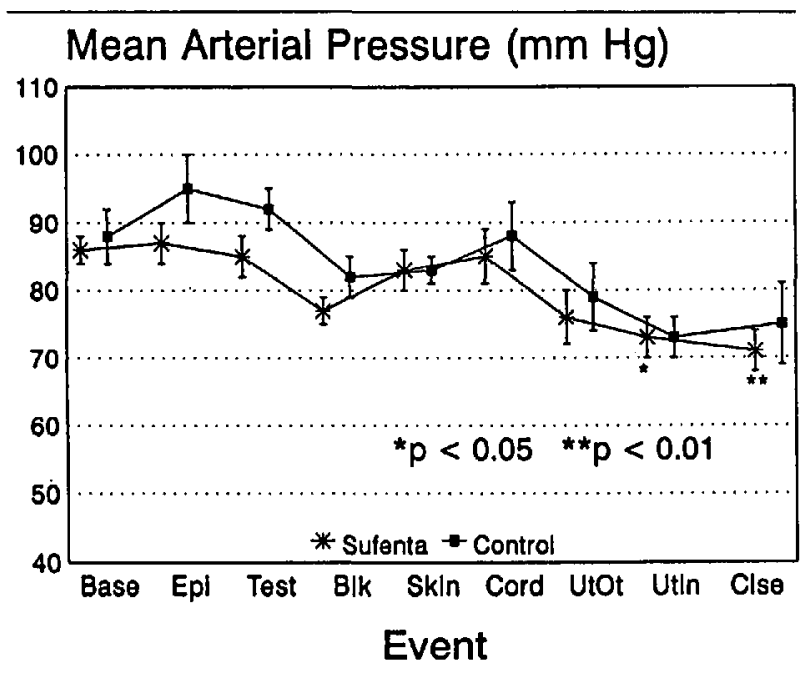

FIGURE 2 Mean arterial pressure. The asterisks denote perioperative events at which the mean arterial pressure was significantly different from the baseline values established in each group.

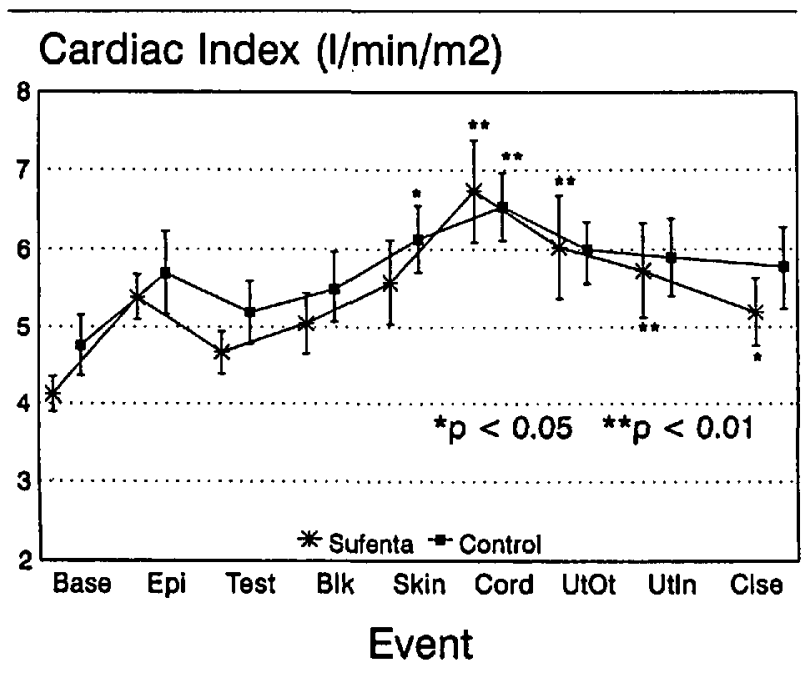

FIGURE 3 Cardiac index. The asterisks denote perioperative events at which the cardiac index was significantly different from the baseline values established in each group.

dural catheter insertion and test dose and was increased in Group C only at the time of epidural catheter insertion (Figure 5).

\section{Discussion}

Maternal haemodynamic measurements as measured by a thoracic electrical bioimpedance computer in normal, healthy parturients during Caesarean section, were not altered by the addition of sufentanil to carbonated lidocaine for lumbar epidural anaesthesia. Differences occurred within the groups, over the perioperative course.

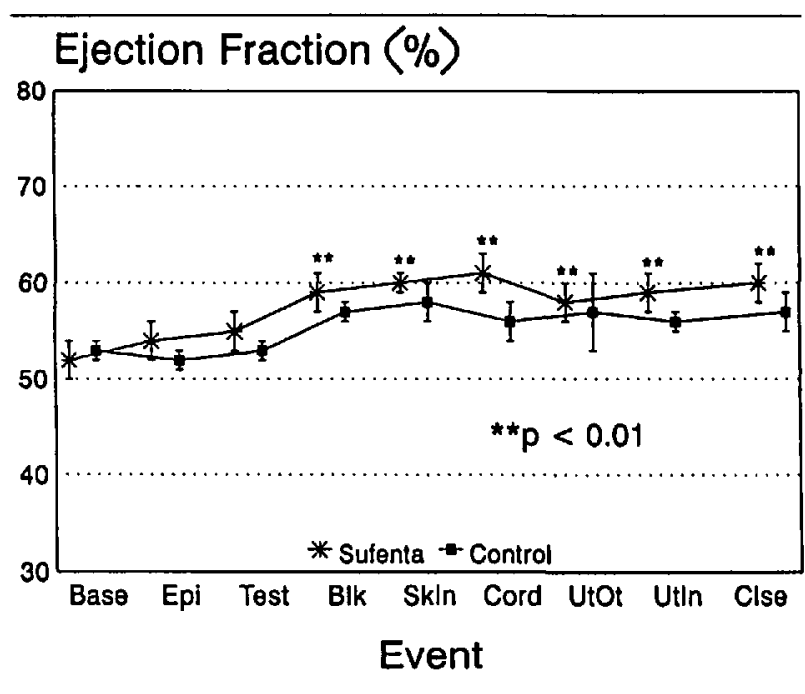

FIGURE 4 Ejection fraction. The asterisks denote perioperative events at which the ejection fraction was significantly different from the baseline values established in each group.

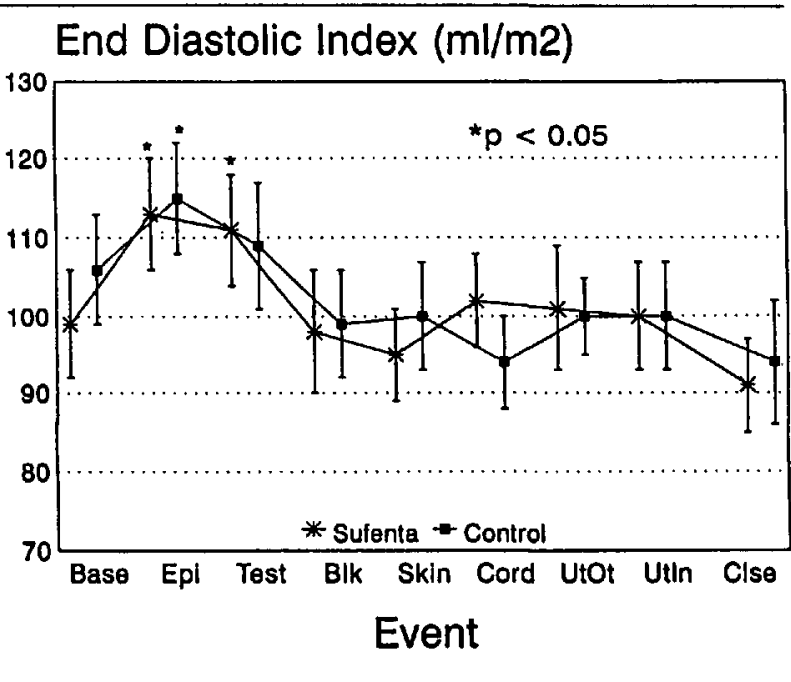

FIGURE 5 End diastolic index. The asterisks denote perioperative events at which the end diastolic index was significantly different from the baseline values established in each group.

Mean arterial pressure was stable in both groups throughout the perioperative period and remained within a clinically acceptable range. The number of interventions (ephedrine $i v$ ) required in each group to maintain stability was the same. Heart rate and cardiac index increased at the onset of surgery and persisted to a variable degree in both groups. The increases were progressive, reached statistical significance with the delivery of the neonate and then abated. The increases in heart rate and cardiac index were proportional and it is likely that the increased heart rate was the major factor in the augmented cardiac 
index. The ejection fraction was increased compared with baseline in Group $\mathrm{S}$ from the time of block development until the end of the study period. A similar trend in ejection fraction was observed in Group $\mathrm{C}$ and although the increases in ejection fraction did not reach statistical significance, there is no clinically important difference between the two groups with respect to ejection fraction. End diastolic index, a measure of preload, was increased early, likely as a result of aggressive $i v$ volume loading. It is possible that our failure to find a difference between the groups reflects a type II error and was a result of our small sample size. Had more patients been studied, the results may have been different. However, the data are so similar between the groups, that it is likely that, if a difference exists, it is of little clinical importance.

The addition of fentanyl to the local anaesthetic solution employed to establish epidural block improves intraoperative analgesia during Caesarean section and reduces the incidence of breakthrough pain, nausea and vomiting. ${ }^{5-7}$ Epidural fentanyl has been shown to provide analgesia of rapid onset and relatively short duration with little respiratory depression and no effect on the neonate. Cohen reported two to four hours of postoperative analgesia when 30-50 $\mu \mathrm{g}$ sufentanil were administered into the epidural space following Caesarean delivery. ${ }^{8}$ Onset of analgesia was rapid in Cohen's study and the incidence of maternal side effects was low, especially when $30 \mu \mathrm{g}$ was the administered dose. Although not the main focus of this investigation, we did not find a difference in either the incidence of pain, nausea or vomiting or the requirement for supplemental analgesics between the two groups in our study. Our overall incidence of intraoperative pain $(2 / 21=9.5 \%)$ is much lower than the $35-55 \%$ incidence reported by others but it is consistent with our clinical experience..$^{5-7}$ Other investigators have combined bupivacaine $0.5 \%$ with fentanyl and this may explain their findings of increased intraoperative pain relative to our data. ${ }^{5,6}$ Further, it is possible that our failure to detect a difference between the groups again reflects a type II error and is due to an inadequate number of patients being studied. If we assume that our incidence of breakthrough pain of $10 \%$ is true for our population and if we consider that a clinically important result. would be a reduction to $5 \%$ with epidural sufentanil, nearly 350 patients would be needed to generate sufficient power to declare that no difference exists between the two groups should a negative result be obtained.

Epidural sufentanil probably offers little advantage over fentanyl as an adjunct to epidural anaesthesia for Caesarean section. There is no evidence that it is a more effective adjunct in that the duration of analgesia is not increased and or side-effects are not reduced compared with fentanyl. ${ }^{9}$ The potency ratio of epidural sufentanil to fentanyl appears to be less than that seen after intravenous administration with $20-30 \mu \mathrm{g}$ of epidural sufentanil providing similar analgesia to $50-100 \mu \mathrm{g}$ of epidural fentanyl. A misplaced, intravenous injection of 30 $\mu \mathrm{g}$ sufentanil presents a greater risk of respiratory compromise to the parturient than does $50-75 \mu \mathrm{g}$ of fentanyl.

Our haemodynamic findings are consistent with those reported by others. ${ }^{2,10}$ Preloading increased end-diastolic index and there was a similar trend upwards with respect to cardiac index although this change did not reach significance in either group. With induction of epidural block there was a downward trend with a return towards baseline values. Robson reported a similar finding when using echocardiography to evaluate the effect of preloading and initiation of epidural block for Caesarean section in 20 term parturients. ${ }^{2}$ Ueland reported a maximal increase in cardiac output immediately following delivery and our findings demonstrated the same. ${ }^{10}$ This probably results from both the increased venous return that occurs with the reduction in the capacity of the uterine vascular bed as well as an emotionally driven sympathetic response on the part of the mother.

Thoracic electrical bioimpedance monitoring measures the resistance of the thorax to the flow of a high frequency, constant, low magnitude alternating current. The high frequency and low magnitude of the measurement current makes the process unperceivable to the subject. Measurement of thoracic impedance produces a steady state component and a pulsatile component. The steady state component, formerly referred to as the basic impedance is now referred to as the thoracic fluid index (TFI) and reflects the volume of intrathoracic fluids. An increase in thoracic fluid will result in decreased thoracic impedance. Blood pumping produces impedance changes measured as plethysmographic and velocity-related components. These pulsatile components are processed by the TEB computer to generate the calculated haemodynamic variables. Estimates of cardiac output, end-diastolic volumes (preload) and afterload are generated and these are indexed to the patient's body surface area to estimate cardiac index, end-diastolic index and ejection fraction. To collect the patient data required for the calculation of haemodynamic variables, four electrode pairs are placed on the patient's thorax, two pairs at the root of the neck and two pairs at the diaphragm.

In pregnant subjects, during both the pregnancy and labour, TEB has been demonstrated to correlate well with invasive (dye and thermodilution) techniques. Mean stroke volume, as determined by TEB, is lower than when measured with dye dilution techniques during Caesarean section. ${ }^{4}$ There is no difference between the mean changes in stroke volume determined by the two techniques during serial measurements at Caesarean section. ${ }^{4}$ Therefore, al- 
though bioimpedance monitoring may underestimate cardiac performance initially, it will reliably and accurately trend performance when serial measurements are made. With TEB, the ventricular function of a parturient may be assessed at no risk and at a fraction of the cost of other current invasive and non-invasive methods. Additionally, it can be repeated frequently and measurements may be performed at the patient's bedside. If cardiac dysfunction is suspected in obstetrical patients, TEB monitoring is a logical first step in its assessment. If more accurate measurements of cardiac performance or central filling pressures are required, thermodilution pulmonary artery catheters probably remain the modality to be relied on.

We were not aware of previously published studies which compared central haemodynamic variables in parturients undergoing Caesarean section under epidural anaesthesia with and without epidural opioids. Our data support the conclusion that epidural sufentanil $(30 \mu \mathrm{g})$ added to carbonated lidocaine during the initiation of epidural blockade for Caesarean section has no clinically important effects on maternal central haemodynamic measurements.

\section{References}

1 Cheek $T G$, Gutsche BB. Maternal physiologic alterations during pregnancy. In: Shnider SM, Levinson G (Eds.). Anesthesia for Obstetrics, 3rd ed. Baltimore: Williams \& Wilkins, 1993; 3-17.

2 Robson $S$, Hunter $S$, Boys $R$, Dunlop W, Bryson $M$. Changes in cardiac output during epidural anaesthesia for Caesarean section. Anaesthesia 1989; 43: 475-9.

3 Secher NJ, Arnsbo P, Anderson LH, Thomsen A. Measurements of cardiac stroke volume in various body positions in pregnancy and during Caesarean section: a comparison between thermodilution and impedance cardiography. Scand J Clin Lab Invest 1979; 39: 569-76.

4 Milsom I, Forssman L, Biber B, Dottori $O$, Sivertsson R. Measurement of cardiac stroke volume during cesarean section: a comparison between impedance cardiography and the dye dilution technique. Acta Anaesthesiol Scand 1983; 27: 421-6.

5 Ackerman WE, Colclough GC, Guiler JM, Guiler DS, Akin JM, Juneja MM. Epidural fentanyl for the management of the pain caused by uterine manipulation during epidural anesthesia for elective cesarean section. Anesthesiology Review 1989; 16: 41-5.

6 Gaffud MP, Bansal P, Lawton C, Velasquez N, Watson $W A$. Surgical analgesia for cesarean delivery with epidural bupivacaine and fentanyl. Anesthesiology 1986; 65: 331-4.

7 Preston $P G$, Rosen $M A$, Hughes $S A$, et al. Epidural anesthesia with fentanyl and lidocaine for cesarean section: ma- ternal effects and neonatal outcome. Anesthesiology 1988; 68: 938-43.

8 Cohen SE, Tan S, White PF. Sufentanil analgesia following cesarean section: epidural versus intravenous administration. Anesthesiology 1988; 68: 129-34.

9 Madej TH, Strunin L. Comparison of epidural fentanyl with sufentanil: analgesia and side effects after a single bolus dose during elective Caesarean section. Anaesthesia 1987; 42: 1156-61.

10 Ueland K, Akamatsu TJ, Eng M, Bonica JJ, Hansen JM. Maternal cardiovascular dynamics. VI. Cesarean section under epidural anesthesia without epinephrine. Am J Obstet Gynecol 1972; 114: 775-80. 